\title{
NEW RECORDS OF LEPTOTHORAX WILSONI FROM WESTERN NORTH AMERICA
}

\author{
By A. Buschinger And R. D. Schumann \\ Institut für Zoologie \\ der Technischen Hochschule Darmstadt \\ Schnittspahnstr.3 \\ D-64287 Darmstadt, FRG
}

\begin{abstract}
The parasitic ant Leptothorax wilsoni Heinze, 1989 was recorded from New Hampshire, Quebec, and New Brunswick. We report on colonies found in two sites in Jasper National Park, Alberta and in one site south of Glacier National Park, Montana. The host species in the west is apparently the same as in the eastern area. Brachypterous intermorphic and fully alate gynomorphic females were found together in two colonies, confirming that $L$. wilsoni is a species with queen polymorphism. L. wilsoni workers and host species queens lacked in all colonies, as in the samples from eastern North America.
\end{abstract}

\section{RESUlts AND Discussion}

The social-parasitic ant Leptothorax wilsoni Heinze, 1989, was reported from three sites in eastern North America: (i) the type locality, Mt. Monadnock, Cheshire Co., New Hampshire (USA); (ii) Mont du Lac des Cygnes, Parque National des Grands Jardins, Québec (Canada); and (iii) Moncton, Westmoreland Co., New Brunswick (Canada). Its most interesting characters are dimorphic queens (ordinary fully alate and brachypterous intermorphic form), and the lack of subapical mandibular teeth. The worker caste is absent.

We report here the recovery of six additional colonies of $L$. wilsoni from three sites in western North America, two from Jasper National Park, Alberta (Canada), and one from the southern border of Glacier National Park, Montana (USA). The new records

Manuscript received 28 September 1993. 
considerably extend the known distribution. They further confirm conspecificity of brachypterous and gynomorphic queens, lack of the worker caste and the absence of host species queens in parasitized colonies.

The L. wilsoni colonies were collected during a field study which was aimed at gathering more information on the enigmatic species Doronomyrmex pocahontas (Buschinger 1979, Buschinger and Heinze 1993), once believed to be an inquiline, and on the inquiline Leptothorax faberi Buschinger, 1981, both described from Jasper National Park, Alberta.

All L. wilsoni colonies were found in decaying wood, in rotting branches or logs on the forest floor. The host species is an undescribed, comparatively large, dark brown to black Leptothorax species belonging to the $L$. "muscorum"-complex. Under the tentative assumption that this is the same as the host species of $L$. wilsoni in eastern North America, we will refer to it here as Leptothorax sp. B (cf. Heinze 1989). The same species was parasitized by $L$. faberi, which was collected only once.

The following are new data of $L$. wilsoni:

\# 1: 29 July 1993, Canada, Alberta, Jasper National Park, Mt. Edith Cavell Road, close to first lookout point coming uproad from HWY 93 A, elevation ca. $1500 \mathrm{~m}$, in a small clearing with surrounding dense pine forest, at the edge of the steep slope to Astoria River. The colony comprised one slightly physogastric dealate intermorphic queen of $L$. wilsoni, four intermorph pupae from which brachypterous intermorphs hatched a few days later, and nine host species workers.

\# 2: Same as before, about one meter from the first colony: One physogastric $L$. wilsoni gynomorph, one alate gynomorph, seven brachypterous intermorphs, seventeen wilsoni- and three host species male pupae, and four host workers.

\# 3: 30 July 1993, Canada, Alberta, Jasper National Park, east of HWY 93, about $10 \mathrm{~km}$ south of Sunwapta Falls, ca. 1800 $\mathrm{m}$, in a rocky landslide area with few scattered pine trees. The colony comprised one male and three alate gynomorphs 
of L. wilsoni, and ten host workers. Since no queen and brood were present it was probably a declining colony.

\# 4: Same as before, about $20 \mathrm{~m}$ from \# 3. No wilsoni and no host queen, but nine alate gynomorphs, twenty-four brachypterous intermorphs (including pupae), five wilsoni males, and about forty host workers.

\# 5: 6 August 1993, USA, Montana, south of Glacier National Park, Pike Creek Road \# 820 at Marias Pass, $1600 \mathrm{~m}$, about $500 \mathrm{~m}$ uproad, in an open, logged pine forest. One gynomorphic queen, eleven males and four male pupae of $L$. wilsoni, and seventeen host workers. The colony was completely collected.

\# 6: Same as before, about five $\mathrm{m}$ from \# 5, in a rotting log of 4-5 m length. One $L$. wilsoni gynomorph and a few gynomorph and male pupae. Unfortunately the wilsoni colony was aspirated together with a large neighboring host colony nesting in the same crevice of the log. The wilsoni queen and her offspring were quickly dismembered and destroyed by workers of this queenright colony.

Our new records are remarkable and deserve discussion for several reasons:

(I) The new sites are located more than $3000 \mathrm{~km}$ west of the previously known range of $L$. wilsoni. It may be suspected that the range extends throughout the belt of subarctic to arctic coniferous forest from eastern US and Canada, at least to the newly detected sites in the Rocky Mountains.

(II) In at least two of our colonies (\# 2 and \# 4) brachypterous intermorphs and gynomorphs co-occurred. In colony \# 2 a gynomorph most probably had produced both gynomorphic and intermorphic offspring. This strongly corroborates the assumption of Heinze (1989) that the two queen forms do not represent separate taxa. Both morphs were present in the two sites in Alberta, whereas only gynomorphs could be found in the two colonies from 
Montana. In eastern North America the intermorphs predominate in the material described by Heinze (1989).

(III) Morphologically the new material exactly matches the specimens described from the eastern localities: Compared to ordinary Leptothorax species the male petiole has a very low node, female mandibles have rudimentary subapical teeth, the gynomorph thorax is bulky, the wings of the intermorphs are reduced in the same way as depicted by Heinze (1989), the postpetiole is armed with a ventral tooth both in males and females, and both female morphs have a dense foveate-reticulate sculpture except for the shiny gaster. The wing venation of male and gynomorph is largely identical to that of the host gyne as depicted in Heinze (1989).

Queen dimorphism occurs in both areas. We suspect that long range dispersal occurs with fully alate females, and that local colonization with brachypterous flightless queens is of some selective advantage for $L$. wilsoni, as was demonstrated for Leptothorax sp. A in eastern North America (Buschinger and Heinze 1992). It is difficult to speculate about the selective value of queen dimorphism in L. wilsoni as yet. According to our observations in Alberta and Montana, the host species (Leptothorax sp. B) is widespread and occurs in considerable densities, which are not markedly higher in the sites where we found $L$. wilsoni than in surrounding forests. One common feature of all three new sites, however, is that the forest is clearly less dense than in neighboring stands where we found the host species only. Colonies \# 3 and \# 4 were in a rocky landslide area with only few trees. Assuming that L. wilsoni needs more insolation and higher temperatures than its host species, it might be useful to have flightless queens colonizing such favorable climatic islands, as well as fully winged queens that may be able to reach similar distant sites.

(IV) The new material confirms the absence of host species queens in parasitized colonies, and the monogyny of $L$. wilsoni. Heinze (1989) described fighting between newly mated wilsoni intermorphs and the apparent elimination of a host queen through stinging by a parasite queen. Other corresponding features are the apparently small size of parasitized colonies both in eastern and western North America, and the relative rarity of the parasite. Mature $L$. sp. B colonies often comprise 100-200 workers. 
(V) Finally, the parasite complex related to Leptothorax sp. B, if it is the same species in eastern and western North America, represents a stunning parallel to that associated with the European $L$. acervorum: The latter is the main host of the slavemaking Harpagoxenus sublaevis, the exclusive host of Doronomyrmex pacis and $D$. kutteri (both workerless inquilines), and of $D$. goesswaldi, which eliminates the acervorum queens by cutting off their antennae (Buschinger and Klump 1988). Leptothorax sp. B is the main host of the slavemaker Harpagoxenus canadensis in eastern North America (Heinze et al. 1992), host of the inquilines $L$. faberi (Buschinger 1981) and L. paraxenus (Heinze and Alloway 1991), and host of $L$. wilsoni, which apparently eliminates the host colony queen!

As with the European group of parasites of $L$. acervorum (Buschinger 1990), the phylogenetic relationships of the parasites and their common host species are as yet unknown. Heinze (1991) provided evidence from isozyme patterns that $L$. paraxenus is more closely related to a group of "small brown" Leptothorax species, including $L$. sp. A, than to its host $L$. sp. B. Queen polymorphism is unknown in European free-living Leptothorax s. str. (L. acervorum, muscorum, gredleri, scamni) and in the permanent parasites of genus Doronomyrmex; however, it occurs in the slavemaker Harpagoxenus sublaevis. In contrast, the American H. canadensis has only gynomorphic queens, whereas the parasites $L$. wilsoni and $L$. paraxenus both have dimorphic queens, as do the free-living Leptothorax sp. A and L. sphagnicolus Francoeur, 1986. Perhaps queen polymorphism in this group is another indicator of a close relationship between Leptothorax sp. A and the two parasites of $L$. sp. B.

\section{REFERENCES}

Buschinger, A. 1979. Doronomyrmex pocahontas n.sp., a parasitic ant from Alberta, Canada (Hym., Formicidae). Ins. Soc. 26: 216-222.

1981. Leptothorax faberi n.sp., an apparently parasitic ant from Jasper National Park, Canada (Hymenoptera: Formicidae). Psyche 89: 197-209.

- 1990. Sympatric speciation and radiative evolution of socially parasitic ants-Heretic hypotheses and their factual background. Z. zool. Syst. Evolut.forsch. 28: 241-260.

Buschinger, A., and Heinze, J. 1992. Polymorphism of female reproductives in ants. In: Biology and Evolution of Social Insects (J. Billen, ed.), Leuven Univ. Press, Leuven (Belgium), 11-23. 
1993. Doronomyrmex pocahontas: not a workerless parasite but still an enigmatic taxon (Hymenoptera, Formicidae). Ins. Soc. 40: 423-432.

Buschinger, A., and Klump, B. 1988. Novel strategy of host colony exploitation in a permanently parasitic ant, Doronomyrmex goesswaldi. Naturwissenschaften 75: 577-578.

Heinze, J. 1989. Leptothorax wilsoni n.sp., a new parasitic ant from eastern North America (Hymenoptera: Formicidae). Psyche 96: 49-61.

1991. Biochemical studies on the relationship between socially parasitic ants and their hosts. Biochem. Syst. Ecol. 19: 195-206.

Heinze, J., and Alloway, T. M. 1991. Leptothorax paraxenus n.sp., a workerless social parasite from North America (Hymenoptera: Formicidae). Psyche 98: 195-206.

Heinze, J.; Stuart, R. J.; Alloway, T. M.; and Buschinger, A. 1992. Host specificity in the slave-making ant Harpagoxenus canadensis M. R. Smith. Can. J. Zool. 70: $167-170$. 

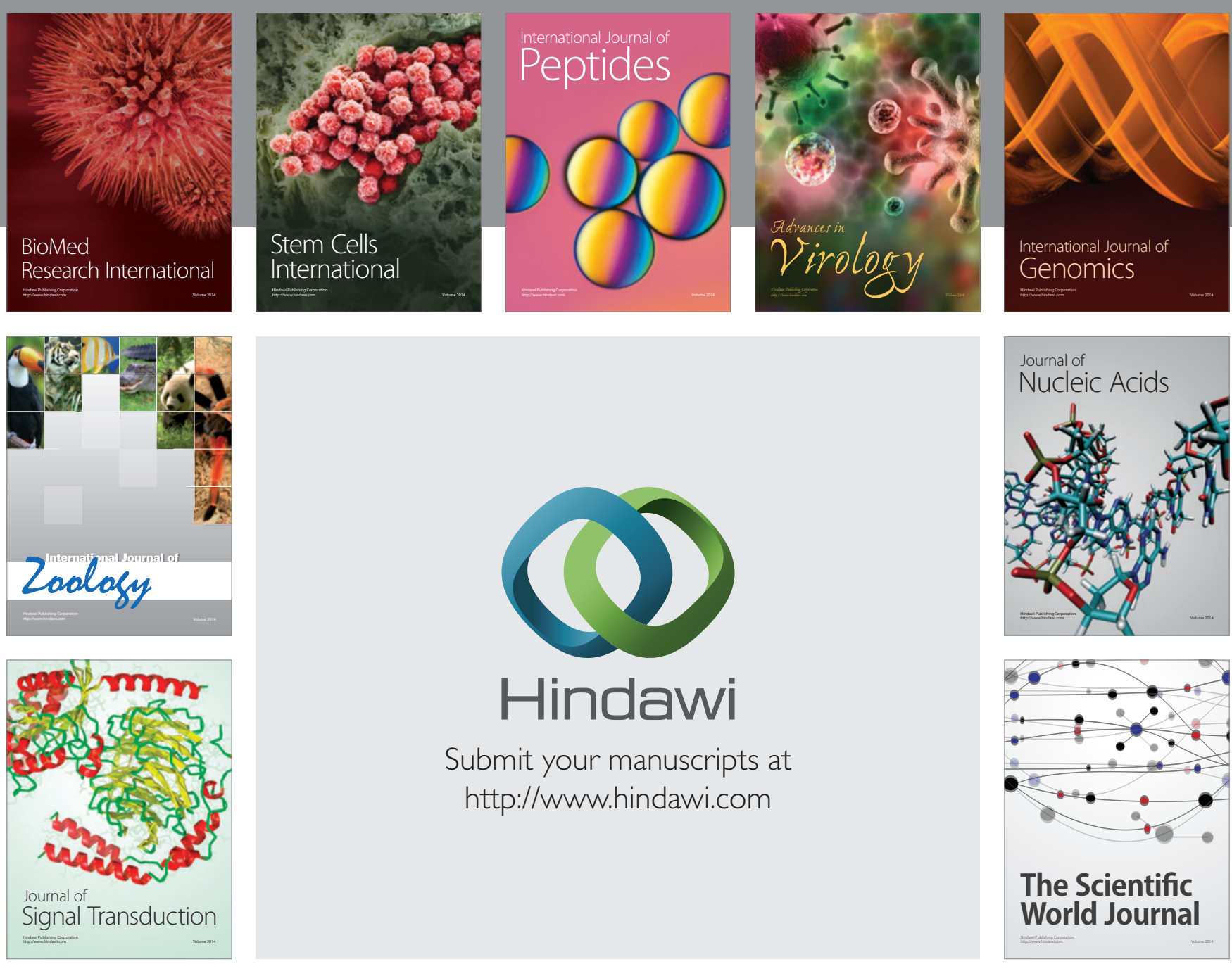

Submit your manuscripts at

http://www.hindawi.com
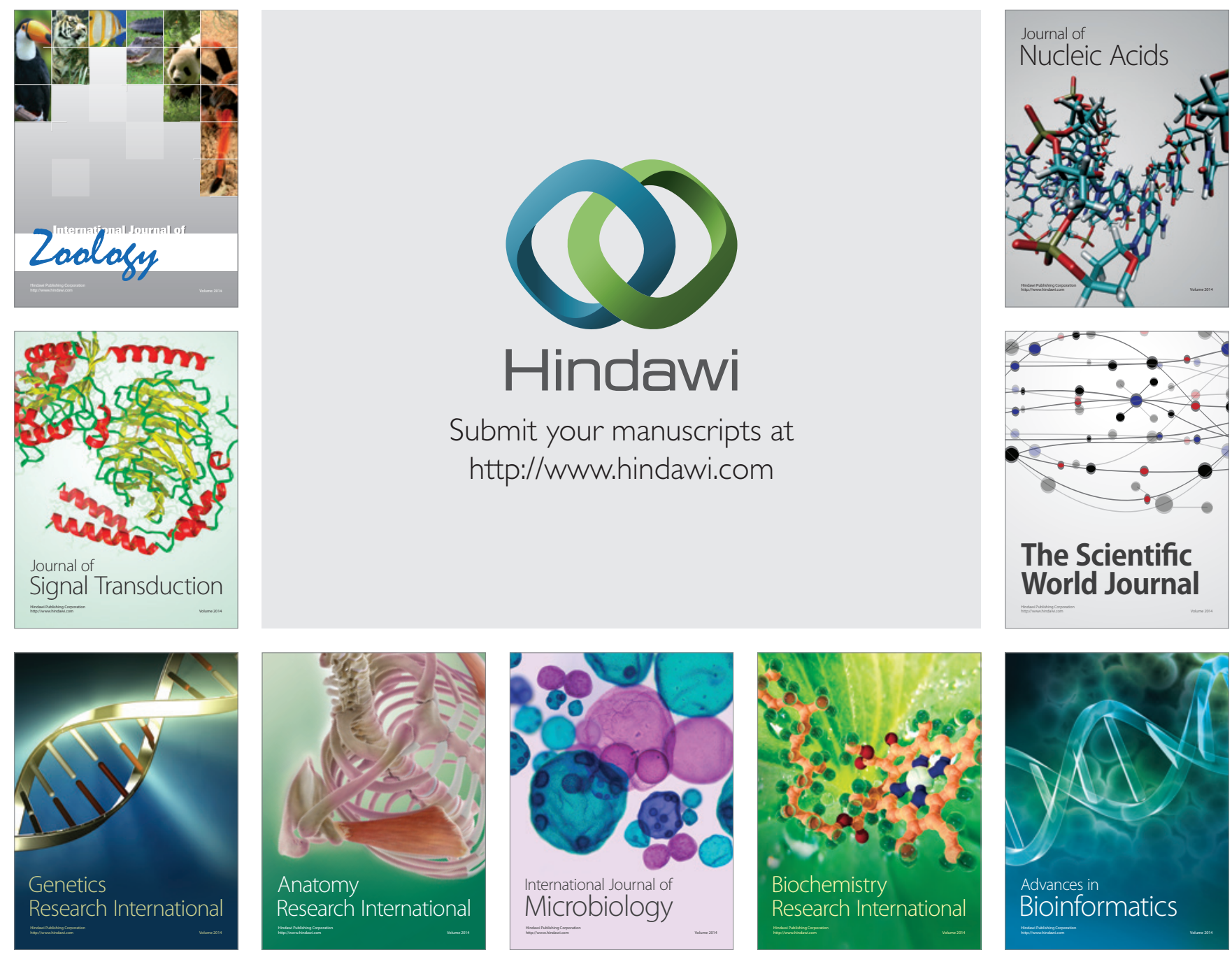

The Scientific World Journal
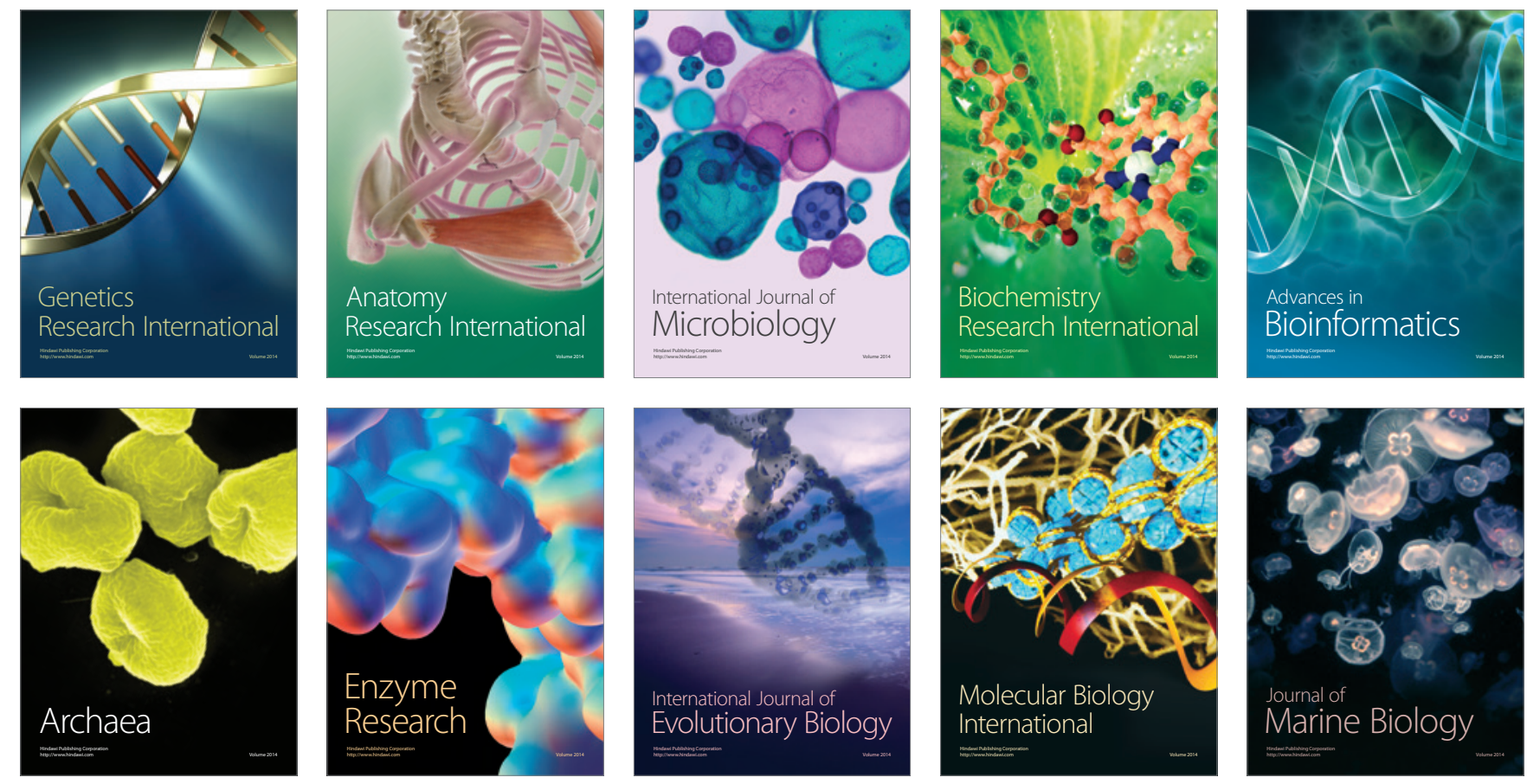